\title{
OBSERVATIONS ON THE CAUSE AND MECHANISM OF SYMPTOM-PRODUCTION IN SCIATICA AND LOW-BACK PAIN
}

BY

\author{
MURRAY A. FALCONER, MURRAY McGeORge, and A. CHARLES BEgG
}

From the Departments of Neurosurgery, Medicine, and Diagnostic Radiology of the Otago University Medical School and the Dunedin Hospital, New Zealand

(RECEIVED FOR PUBLICATION, OCTOBER 15, 1947)

INDEX

INTRODUCTION ..

OBSERVATIONS ON THE ETIOLOGY OF ScIATICA AND

Low-BACK PAIN " A. In "surgical "cases of sciatica and low-back

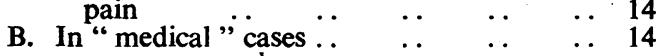

Observations on the Mechanism of Symptom-

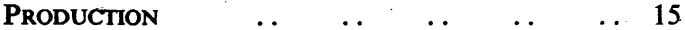

A. Concerning disc prolapses .. $\quad \ldots \quad \ldots \quad$. 15

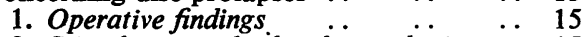

2. Stimulation under local anasthesia .. 15

3. Fluctuations in size $\quad . \quad \ldots \quad \ldots \quad \ldots \quad 15$

4. Position in relation to theca and nerve roots .. $\quad \ldots . \quad \ldots \quad \ldots . \quad \ldots \quad 15$

5. Myelographic observations after spontaneous disappearance of symptoms..

6. Operative observations after the spontaneous disappearance of symptoms. .

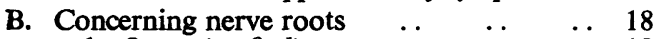

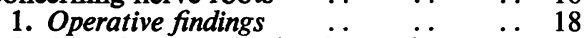

2. Stimulation under local anasthesia $\quad . \quad 19$

3. Transmission of impulses through

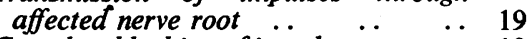

4. Complete blocking of impulses.. . . . 19

5. Relation of neurological signs to affected nerve roots $\quad . . \quad \ldots \quad 19$

6. Significance of certain general signs .. 20

7. Observations on straight-leg raising .. 20

8. Types of strain involving nerve roots .. 20

9. Significance of straight-leg raising test : Evidence for variations in length of affected nerve roots

10. Observations in case of sciatica due to a hydatid cyst .. . . . .

11. Nature of pathological changes within affected nerve roots ... .. .. 22

C. Other observations $\quad \ldots \quad \ldots \quad \ldots 22$

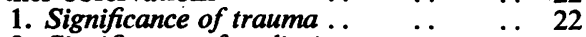

2. Significance of scoliosis $\quad$. $\quad \ldots 23$

3. Level of protein in cerebrospinal fluid. . 23

4. Miscellaneous observations .. $\quad . .23$

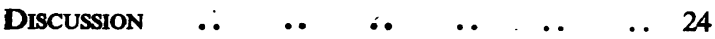

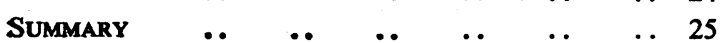


similar findings indicating disc prolapse on myelography, suggesting that disc prolapse was the common cause of symptoms in the second group, as in the first. Myelography, however, when repeated after recovery in those cases in which symptoms subsided without operation, indicated that the disc prolapses were still there. This led us to make further inquiries, and our observations will now be discussed in more detail.

\section{OBSERVATIONS ON FTIOLOGY OF SCIATICA AND LOW-BACK PAIN}

\section{A. In "Surgical" Cases of Sciatica and Low-Back Pain}

The myelographic and operative findings in this group have already been discussed in some detail (Begg, Falconer, and McGeorge, 1946 ; Falconer, McGeorge, and Begg, 1948). The patients were referred to us for surgical treatment from many parts of New Zealand during a period of two years. Before operation most had had complete rest in bed for a month or more without relief of disabling symptoms. In 77 of the hundred cases in this group intractable sciatica was the predominant symptom, and in each of these disc prolapses were found and dealt with at operation, with improvement or relief of symptoms in every case, although in some instances more than one operation was required. This indicates that disc lesions are the cause of symptoms in this group (Falconer and others, 1948). In the remaining 23 cases, severe low-back pain predominated or occurred alone, and in all but one of these disc prolapses were shown at operation to be present, while improvement or relief of symptoms followed in all but two. During the period in which this group of 100 cases was being collected, only two other cases with sciatic pain of a severity and intractability necessitating operation came under our notice, and in both of these tumours affecting the cauda equina had caused the symptoms. We concluded, therefore, that disc prolapses must be the only common cause of sciatica which is both severe and intractable, and also probably, of severe and intractable low-back pain.

Myelography was performed before operation in 95 of the " surgical " cases, although in the cases of "sciatica" the diagnosis was based upon clinical findings alone, and, if the clinical signs were deemed sufficient, operation was carried out whether the myelogram was positive or negative. A positive myelogram, however, was required before operation was undertaken in the presence of low-back pain alone (Falconer and others, 1948). In 9 cases the findings were obscured by artefacts due to faulty tèchnique, leaving 86 cases which were examined satisfactorily. In 88 per cent. of these the myelo- graphic appearances were deemed pathological, and subsequently at operation the level of the disc prolapse was confirmed in almost every instance (74 out of 76 cases). Only in 12 per cent. of cases were the myelographic appearances considered normal. We concluded, therefore, that myelography could demonstrate disc lesions in most cases, and that when it was positive it was reliable. A negative myelogram, however, does not exclude a disc lesion.

\section{B. In "Medical" Cases}

During a period of three and a half years commencing with, but extending beyond, the period in which the "surgical" cases were being collected, approximately 400 patients were seen by us through the courtesy of our colleagues, mostly as outpatients, from the city and rural district immediately surrounding the hospital. These patients by and large presented the same histories and the same signs as did the "surgical" cases, but in most instances the symptoms were milder or else responded to domiciliary treatment. Some 83 cases in this series, however, had severe symptoms which necessitated their admission to hospital, and it is from these $\mathbf{8 3}$ cases that our second group is taken. Some had complained of symptoms intermittently for many years and for long periods at a time; others had developed their first symptoms only recently. Many had previously received physiotherapy without lasting benefit, but very few had been treated by complete rest in bed for more than a week or two. As the only difference between these cases and those not admitted to hospital was one of severity of symptoms, we may regard this group of in-patients as representative of the great mass of sufferers with sciatica and low-back pain, whose symptoms are disabling but who have not yet received adequate medical treatment.

All cases in this " medical "group were examined by myelography according to the same technique as the surgical group and were then treated conservatively by complete rest in bed for at least four weeks, either in hospital, or, after investigations were completed, in their own homes. Of the 83 cases, 7 can be excluded from further consideration, 2 of these because the myelograms were obscured by artefacts, and 5 because their symptoms and disability were dubious. These 5 cases were all seeking compensation for back pain referable to an injury, and had no definite physical signs, normal radiographs of the spine, and normal myelograms.

This leaves 76 cases suffering from leg and/or low-back pain, which were examined satisfactorily by myelography and which were studied in our second group. In 52 cases sciatica predominated, 
in 2 anterior crural pain was present, while in the remaining 22 cases low-back pain predominated or occurred alone. All cases showed physical signs, such as exacerbation of pain on coughing or sneezing, rigidity of the lumbar spine, limitation of straightleg raising, although in some these signs were only slight. In respect of physical signs, however, this " medical" group of cases was essentially similar to the " surgical" group. Of the 76 cases, 32 (42 per cent.) recovered without operation and have since remained symptom-free, whereas 44 ( 58 per cent.) either failed to respond to rest in bed or else, after a period of temporary remission, again developed recurrent symptoms and were then submitted to operation. Thus approximately 1 in 9 of the "medical" cases we were asked to see was eventually treated surgically, and a disc lesion was demonstrated in almost every case.

Myelography revealed abnormalities indicative of disc protrusions in 88 per cent. of these cases (67 cases), while no abnormality was discovered in 12 per cent. (9 cases). As the frequency with which myelography revealed positive findings is the same as in the operated group, it is difficult to come to any conclusion other than that disc protrusions must have been present in the "medical" cases in the same proportion as in the " surgical" cases, that is, in practically every case. The confirmation of disc prolapse in each " medical" case which eventually -came to operation and the subsequent improvement in symptoms supports this deduction.

\section{OBSERVATIONS ON MECHANISM OF SYMPTOM- PRODUCTION}

Granted then that disc prolapses are of almost universal occurrence in cases of sciatica and lowback pain, the question next arises as to how they produce symptoms. In this connexion we have collected a number of observations that appear relevant.

\section{A. Concerning Disc Prolapses}

1. Operative Findings.- In the course of our operative experience we have noted that when symptoms of sciatica are present the disc prolapse is so situated that it abuts upon a nerve root in its course lateral to the theca, either the fifth lumbar nerve at the level of the fourth lumbar disc or the first sacral nerve at the fifth lumbar disc. However, when low-back pain occurs alone, the disc prolapse is so situated that, although it may indent and compress the theca, it does not involve a nerve root in its extrathecal course. The roots of the cauda equina within the theca are mobile and can slip away from any lesion narrowing the theca, unless it be large enough to occlude the thecal lumen completely.
The extrathecal nerve roots, however, are more fixed in their short course between two anchoring points, the point at which each emerges from the theca, and the point at which each passes into the intervertebral foramen. Consequently the extrathecal nerve root cannot easily slip away from a disc protrusion (O'Connell, 1943).

2. Stimulation under Local Anæsthesia.-The presence of a disc prolapse alone will produce lowback pain, but some degree of nerve-root compression is necessary to produce sciatica. In a few . patients with sciatica and low-back pain operated on under local anæsthesia, we found that pressure with a probe on the disc prolapse reproduces lowback pain, whereas pressure on either the fifth lumbar or first sacral nerve root reproduces sciatic pain.

3. Fluctuations in Size.-The size of many, though probably not all, disc protrusions fluctuates with the degree of weight-bearing and other torsional strains imposed upon the affected disc. We have for example shown, both at operation and by myelography, that the prominence of many prolapses is increased by hyperextension of the spine and also by weight-bearing, particularly in the class of disc prolapse which we term " intermittent." Knutsson (1942) appears to have made similar observations in cadaver specimens. Thus in recumbency the size of many disc protrusions is less than during activity.

4. Position in Relation to Theca and Nerve Roots.The siting of a disc prolapse in relation to the theca and nerve roots is governed by anatomical arrangements (Falconer, 1944). Most intraspinal disc prolapses protrude to one side of the posterior longitudinal ligament, and when situated at the fourth and fifth lumbar interspaces have an opportunity of compressing extrathecal nerve roots, for these are the only two spaces which are customarily crossed by nerve roots in their extrathecal course (Fig. 1). Sometimes the fourth lumbar nerve in its course lateral to the theca comes into relation with the third lumbar disc, and a laterally placed protrusion here may lead to anterior crural pain. Most disc prolapses, however, at this and higher levels are so placed that they cannot produce nerve-root compression, and consequently they remain symptomless or cause only back pain. Again, we have operated on a few cases of low-back pain and found a large disc prolapse at the fourth lumbar level which was not causing sciatica, presumably because in these particular cases the fifth lumbar nerve roots on either side emerged through the theca below the level of this disc.

In a smaller proportion of cases the disc prolapse is situated in the midline anterior to the theca. Such 
cases are commonly characterized by repeated attacks of low-back pain, and do not exhibit sciatica unless the disc prolapse is sufficiently broad to extend far enough laterally on one or both sides to implicate a nerve root situated lateral to the theca. -As might be expected, such broad central prolapses are often associated with bilateral sciatica. In some cases pain is present in both legs simultaneously. In other cases it alternates from one leg to the other, presumably secondary to slight alterations in the contour of the prolapse, which bulges slightly more, first to one side and then to the other. Occasionally a patient is encountered who can voluntarily change both the direction of his sciatic scoliosis and the side of his pain by wriggling and twisting his lumbar spine.

5. Myelographic Observations after Spontaneous Disappearance of Symptoms.-The suddenness with which symptoms may appear or pass off, particularly in sciatica, but also in low-back pain, would seem to suggest that disc prolapses may appear suddenly, and reduce themselves equally as rapidly. Undoubtedly this does happen, especially when a disc prolapse, as for example an extrusion, develops immediately after a sudden and severe trauma, while certain disc prolapses can be shown by myelography to alter in size with changes in the torsional strains applied to the back (Begg and others, 1946). Moreover, post-mortem studies. of human spinal columns have indicated that gradual healing of posterior disc prolapses can occur (Beadle, 1931 ; Rabinovitch, 1947). But a noticeable alteration in the size of a disc prolapse does not always accompany the appearance or disappearance of symptoms in sciatica or low-back pain, and in this connexion we have made an unexpected set of observations, namely that when symptoms pass off either spontaneously or after rest in bed the disc prolapse often persists apparently unchanged in size.

This observation was made in 10 patients admitted to the medical wards with acute symptoms of recent onset, who all recovered rapidly and completely with rest in bed (Table 1). Each had characteristic clinical signs, and when examined during the period of symptoms each showed positive myelographic evidence of a disc prolapse. Subsequently, at periods varying from one to fifteen months after cessation of symptoms, myelography was repeated, and in most instances the radiographic silhouette of the disc protrusion was found to have persisted unaltered. Only in the patient, in whom the myelogram was repeated fifteen months after recovery from symptoms, did the appearances suggest a slight recession in size.

Fig. 2 gives an example of the usual myelographic findings. They are from a 45-year-old man (first case in Table I) admitted ry of left anterior crural pain associated with marked scoliosis. Symptoms cleared completely within a few days of admission to hospital. This set of myelograms shows that at the time of acute symptoms he had, in addition to a disc prolapse, swelling of the involved nerve root, but that after symptoms had ceased the swelling of the nerve root disappeared, although the disc prolapse remained the same size.

6. Operative Observation after Spontaneous Disappearance of Symptoms. - In an operated case, not included in this subgroup, we had the opportunity of making a similar observation. This was a man who had had sciatica persistently for eighteen months without being benefited by long periods of rest in bed. A myelogram showed a disc prolapse, but a few hours later all symptoms suddenly disappeared. Next day the man discharged himself from hospital, but within forty-eight hours he was back again with a severe recurrence. Three days later his symptoms again disappeared, but myelography when repeated showed the disc prolapse to be still apparently unaltered. The patient asked for operation, and in due course a typical disc projection at the fourth lumbar space was found and removed. The nerve root was noted to be easily movable over the prolapse and not taut. Since operation the patient has remained symptom-free for four years.

It would seem then that the spontaneous disappearance of symptoms in sciatica or low-back pain is not necessarily due to the disappearance of the disc prolapse, and furthermore that a disc prolapse may be present without symptoms. Similarly, although in many instances a sudden onset of symptoms is undoubtedly due to a sudden 

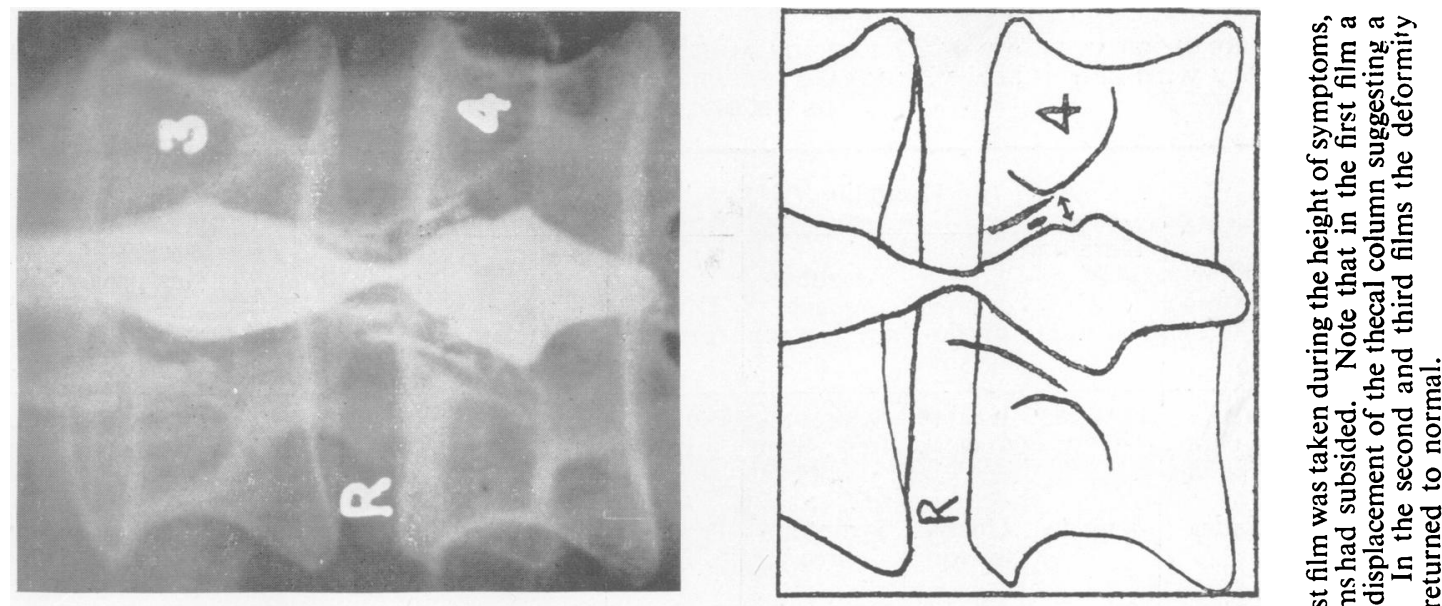

है:

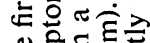
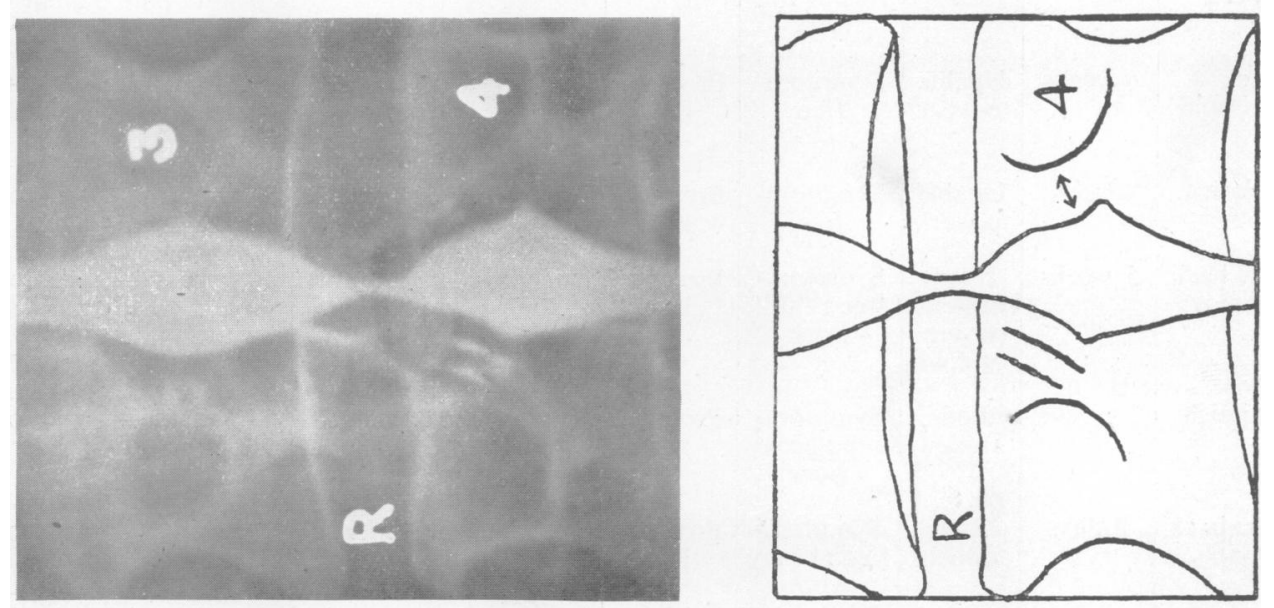

을.은

$\rightarrow$ ⿵人丶龴

त示完

产部.

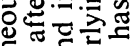

제유

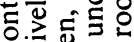

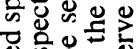

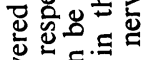

วิ

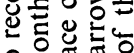

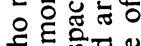

उत कृष्य

Co

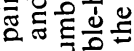

뚠흐음을

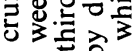
on 0 品

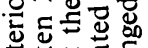

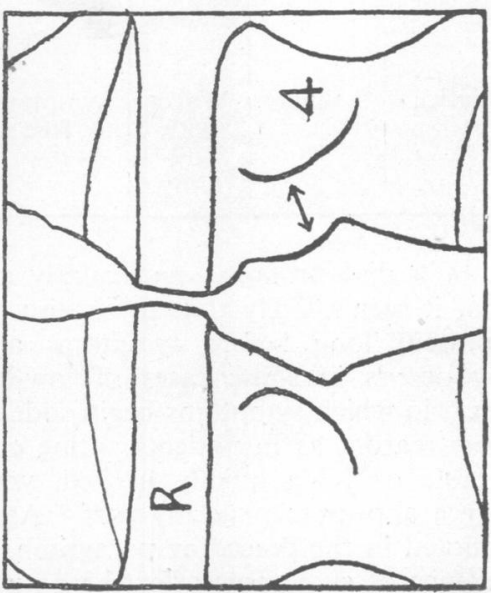

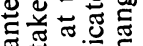

ब.

过 운

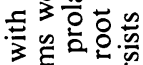

政西

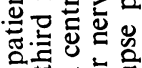

$\pi \approx$

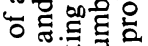

है․ㅡㄹ.

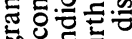

엉.

혗의

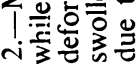


TABLE I

RECORD IN CHRONOLOGICAL ORDER OF 10 PATIENTS ADMITTED WITH "DISC" SYMPTOMS OF ACUTE ONSET WHICH SUBSIDED RAPIDLY WITH REST IN BED. MYELOGRAMS REPEATED AT INTERVALS AFTER RECOVERY DISCLOSED PERSISTENCE OF THE DISC PROLAPSE

\begin{tabular}{|c|c|c|c|c|c|c|c|c|c|}
\hline \multirow[b]{2}{*}{ Sex } & \multirow[b]{2}{*}{ Age } & \multirow[b]{2}{*}{$\begin{array}{l}\text { Leading } \\
\text { symptom }\end{array}$} & \multirow[b]{2}{*}{$\begin{array}{c}\text { Duration } \\
\text { of } \\
\text { leading } \\
\text { symptom }\end{array}$} & \multicolumn{2}{|c|}{ Disability } & \multicolumn{3}{|c|}{ Myelogram } & \multirow[b]{2}{*}{ Later progress } \\
\hline & & & & $\begin{array}{c}\text { At } \\
\text { original } \\
\text { myelo- } \\
\text { gram }\end{array}$ & $\begin{array}{l}\text { At subse- } \\
\text { quent } \\
\text { myelogram }\end{array}$ & $\begin{array}{l}\text { During } \\
\text { attack }\end{array}$ & Subsequent & $\begin{array}{c}\text { Time } \\
\text { interval }\end{array}$ & \\
\hline $\mathbf{M}$ & 45 & $\begin{array}{l}\text { Anterior } \\
\text { leg pain }\end{array}$ & 11 weeks & $\begin{array}{l}\text { Unable } \\
\text { to work }\end{array}$ & $\begin{array}{l}\text { Symptom- } \\
\text { free ; light } \\
\text { work }\end{array}$ & $\begin{array}{l}\text { Prolapse } \\
\text { L } 3\end{array}$ & Unchanged & 2 months & $\begin{array}{l}3 \text { years_symptom-free } \\
\text { heavy work }\end{array}$ \\
\hline $\mathbf{M}$ & 31 & Sciatica & 4 weeks & $\begin{array}{l}\text { Unable } \\
\text { to work }\end{array}$ & $\underset{\text { free }}{\text { Symptom- }}$ & $\begin{array}{l}\text { Prolapse } \\
\text { L } 4\end{array}$ & Unchanged & 1 month & $\begin{array}{l}3 \text { years-symptom-free } \\
\text { heavy work }\end{array}$ \\
\hline $\mathbf{M}$ & 42 & $\begin{array}{c}\text { Low back } \\
\text { pain }\end{array}$ & 2 hours & $\begin{array}{l}\text { Bed- } \\
\text { ridden }\end{array}$ & $\begin{array}{l}\text { Symptom- } \\
\text { free ; full } \\
\text { work }\end{array}$ & $\begin{array}{l}\text { Prolapse } \\
\text { L } 4\end{array}$ & Unchanged & 9 months & $\begin{array}{l}2 \frac{1}{2} \text { years - occasional } \\
\text { slight pain : steady } \\
\text { light work }\end{array}$ \\
\hline $\mathbf{M}$ & 37 & $\begin{array}{l}\text { Back }+ \\
\text { leg pain }\end{array}$ & 6 weeks & $\begin{array}{l}\text { Unable } \\
\text { to work }\end{array}$ & $\begin{array}{c}\text { Symptom- } \\
\text { free }\end{array}$ & $\begin{array}{l}\text { Prolapse } \\
\text { L } 4\end{array}$ & Unchanged & 1 month & $\begin{array}{l}2 \frac{1}{2} \text { years - occasional } \\
\text { back pain ; steady } \\
\text { light work }\end{array}$ \\
\hline $\mathbf{M}$ & 58 & Sciatica & 4 weeks & $\begin{array}{l}\text { Unable } \\
\text { to work }\end{array}$ & $\begin{array}{c}\text { Symptom- } \\
\text { free }\end{array}$ & $\begin{array}{l}\text { Prolapse } \\
\text { L 3 }\end{array}$ & Unchanged & 1 month & $\begin{array}{l}2 \frac{1}{2} \text { years - symptom- } \\
\text { free ; heavy work }\end{array}$ \\
\hline $\mathbf{F}$ & 18 & $\begin{array}{c}\text { Low back } \\
\text { pain }\end{array}$ & 3 weeks & $\begin{array}{l}\text { Inter- } \\
\text { mittent } \\
\text { severe } \\
\text { pain }\end{array}$ & $\begin{array}{l}\text { Symptom- } \\
\text { free ; full } \\
\text { work }\end{array}$ & $\begin{array}{l}\text { Prolapse } \\
\text { L } 4\end{array}$ & Unchanged & 8 months & $\begin{array}{l}1 \frac{1}{2} \text { years - symptom- } \\
\text { free; steady moderate } \\
\text { work }\end{array}$ \\
\hline $\mathbf{M}$ & 32 & Sciatica & 3 weeks & $\begin{array}{l}\text { Bed- } \\
\text { ridden }\end{array}$ & $\begin{array}{l}\text { Symptom- } \\
\text { free ; heavy } \\
\text { work }\end{array}$ & $\begin{array}{l}\text { Prolapse } \\
\text { L } 5\end{array}$ & $\underset{\text { Smaller }}{\text { Similar but }}$ & 15 months & $\begin{array}{l}1 \frac{1}{4} \text { years - symptomo } \\
\text { free; steady moderate } \\
\text { work }\end{array}$ \\
\hline $\mathbf{F}$ & 43 & $\begin{array}{c}\text { Low back } \\
\text { pain }\end{array}$ & 2 days & $\begin{array}{l}\text { Bed- } \\
\text { ridden }\end{array}$ & $\begin{array}{l}\text { Symptom- } \\
\text { free ; heavy } \\
\text { work }\end{array}$ & $\begin{array}{l}\text { Prolapse } \\
\text { L } 3\end{array}$ & Unchanged & 11 months & $\begin{array}{l}9 \text { months - symptom- } \\
\text { free ; heavy work }\end{array}$ \\
\hline $\mathbf{M}$ & 28 & Sciatica & 3 weeks & $\begin{array}{l}\text { Bed- } \\
\text { ridden }\end{array}$ & $\begin{array}{l}\text { Symptom- } \\
\text { free ; full } \\
\text { work }\end{array}$ & $\begin{array}{l}\text { Prolapse } \\
\text { L } 5\end{array}$ & Unchanged & 8 months & $\begin{array}{l}8 \text { months - symptom- } \\
\text { free; steady moderate } \\
\text { work }\end{array}$ \\
\hline $\mathbf{M}$ & 48 & Sciatica & 5 weeks & $\begin{array}{l}\text { Walks } \\
\text { with } \\
\text { diffi- } \\
\text { culty }\end{array}$ & $\begin{array}{c}\text { Symptom- } \\
\text { free }\end{array}$ & $\begin{array}{l}\text { Prolapse } \\
\text { L } 3+4\end{array}$ & Unchanged & 3 weeks & $\begin{array}{l}4 \text { weeks-symptom-free; } \\
\text { not working }\end{array}$ \\
\hline
\end{tabular}

development of a disc prolapse, particularly after severe trauma, it seems likely that some disc prolapses are present long before symptoms arise. This possibly occurs in some cases of low-back pain or sciatica, in which symptoms begin suddenly for no obvious reason, as in patients sitting comfortably at table or lying quietly in bed, where trauma does not appear to play any part. Again, in the case quoted in the preceding paragraph, the sudden recurrence of symptoms after the patient's first discharge from hospital took place in the presence of a disc protrusion known to be already present. Disc prolapse, however, is but one of the two requisites for the production of sciatica, and it is now opportune to pass on and discuss the role of the nerve roots.

\section{B. Observations Concerning Nerve Roots}

1. Operative Findings. - We have already stated that, in our " surgical " patients, whenever there were N symptoms of sciatica the disc prolapse was found to be so situated that it could impinge upon a nerve 
root in its extrathecal course. Often the extrathecal nerve root was flattened, but generally it appeared macroscopically normal. Sometimes on opening the theca the ventral and dorsal components of the involved nerve would together appear congested and swollen to a varying degree, and for a varying extent above and proximal to the orifice of the dural sleeve, through which they leave the theca. This appearance has been noted by others (Holmes and Sworn, 1945 ; Munro, 1945, etc.) and considered by them as evidence of a primary radiculitis. We, however, have always found in such cases that the nerve root was compressed by a disc prolapse just distal to its point of emergence from the theca.

2. Stimulation under Local Anæsthesia.-As stated earlier, during operations under local anæsthesia we have also observed that pressure on either the fifth lumbar or first sacral nerve root with a probe causes radiating crural pain akin to sciatica. Furthermore, we have observed during pre-operative investigations that infiltration of the affected nerve with a local anæsthetic solution at the point where it crosses the disc prolapse will relieve all pain and also such signs as limitation of straight-leg raising (Falconer, Glasgow, and Cole, 1947). Indeed, the infiltration of the extrathecal nerves at each interspace in turn can be used as a diagnostic procedure to determine at which interspace the disc prolapse lies, although the procedure is too formidable for routine use.

3. Transmission of Impulses through Affected Nerve Root.-In association with our colleagues in physiology (D. Malcolm and F.'H. Suckling) we investigated at operation in several patients the speed of transmission of impulses down the affected nerve root as compared with the intact roots, and also the amplitude of the resulting muscular contraction. In this investigation the motor nerve root proximal to the lesion was stimulated intrathecally with a single electric shock of graduated intensity, and the resulting contractions in the calf and foot muscles were recorded electrically by means of surface electrodes placed over the muscles. The action potentials were recorded with a specially constructed amplifier and double-beam oscilloscope incorporating a suitable time marker. Slight delays in conduction of up to 2 milliseconds were sometimes observed in the affected nerve root, while the amplitude of the muscle contraction was usually less. These observations indicated that the degree of blocking of nerve impulses passing through the compressed segment of nerve root was usually only slight. It is this slight blocking of the conduction of impulses through the compressed segment of nerve root, however, which presumably accounts for the neurological features such as slight muscle weakness, slight sensory impairment, and diminution of the ankle jerk, which characterize most cases of sciatica.

4. Complete Blocking of Impulses. - In occasional cases, however, a complete block of the nerve root occurs, leading to such symptoms as foot-drop or cauda equina paralysis. We have observed four cases of foot-drop, and have evidence that the lesion here is a complete blocking of the conduction of impulses through a single nerve root.

In three cases the muscles almost completely paralysed were the tibialis anticus and extensor longus hallucis, while the extensor longus digitorum and the peronei were weakened. In all three the fifth lumbar nerve root was found compressed at operation. We had the opportunity of stimulating the nerve roots at operation in one of these cases, and found that the fifth lumbar nerve root alone would not conduct impulses, whereas the first sacral nerve root conducted normally.

In the fourth case the paralysed muscles included the peronei and the extensor longus digitorum, while the extensor longus hallucis and tibialis anticus muscles were only weakened. The posterior calf muscles and the long flexors of the toes were also markedly weakened in this case, and at operation the first sacral nerve root was found to be involved by a disc prolapse.

All four cases of foot-drop had a characteristic feature in that there had been one or more attacks of sciatica culminating in a very severe episode of pain, which passed off completely but left them with the foot-drop. It seems reasonable to presume that the very severe episode of pain was caused by pressure on the nerve steadily increasing until the nerve was blocked completely, producing muscular and sensory paralysis and also cessation of pain because the nerve root could no longer conduct impulses or be stimulated at the point of compression. In two of our cases some degree of recovery followed slowly after operation. A somewhat similar, but rare, sequence of events is seen in cauda equina paralysis, where a large centrally-placed disc prolapse may invaginate the anterior wall of the theca to such an extent that it compresses the cauda equina.

5. Relation of Neurological Signs to Affected Nerve Root.-The precise neurological signs in sciatica depend upon which nerve root is involved (Falconer, 1944). When the first sacral nerve root is implicated, as by a prolapse at the fifth lumbar interspace, there is commonly though not always a diminution or absence of the ankle jerk, a slight weakness of both plantar flexion and dorsiflexion of the ankle joint, and often a diminution in sensibility within the first sacral dermatome. When the fifth lumbar nerve root is involved, as by a prolapse at the fourth lumbar space, the ankle jerk may be disturbed but generally is intact, there is slight weakness of dorsiflexion of the ankle joint, and often decreased sensibility within the fifth lumbar 
dermatome. These signs are generally well known, although the full extent of the dermatomal patterns has seldom been realized (Falconer and others, 1947). Other common signs include aggravation of pain on coughing or sneezing, rigidity and flattening of the lumbar spine, and limitation of straight-leg raising.

6. Significance of Certain General Signs.-One of the most characteristic signs in sciatica and lowback pain due to disc protrusion is exacerbation of pain on coughing or sneezing. This is of course a feature of "root pain" in general. Those who have observed, either at operation under local anæsthesia or more readily during the performance of myelography, the sudden distension of the theca which accompanies these movements, will readily appreciate how sudden and presumably painful angulating strains are provoked in any extrathecal nerve root which may straddle a disc protrusion. Also any sudden jarring movement of the spinal column may alter the tensions within the disc prolapse itself, and in a proportion of cases will affect its size.

Rigidity and flattening of the lumbar spine are seen in many cases of low-back pain occurring by itself, as well as in most cases of sciatica. The rigidity results from spasm of the spinal muscles, and presumably is a protective reflex mechanism designed to splint the lumbar spine in a position where the degree of prominence of a disc prolapse is lessened and any further torsional strains which might increase its size are avoided. The flattening results from some degree of obliteration of the normal lumbar lordosis, and presumably is due to the same mechanism. Begg and others (1946) have shown, both at operation and by myelography, that extension of the lumbar spine will increase the backward prominence of some disc protrusions. The splinting of the spine in a position of slight flexion probably obviates this latter factor.

7. Observations on Straight-Leg Raising.Another characteristic and paramount sign of sciatica is the limitation of straight-leg raising, and we have made two parallel sets of observations on its mode of production which help to explain much of the pathogenesis of sciatica. The first set of observations was made on a few patients with sciatica during operations performed under general anasthesia. These patients were placed on their sides and the disc lesion was exposed. As the straight-leg raising test was carried out, the affected nerve root was found to tighten over the summit of the protrusion, in many instances burying itself into the protrusion. It was noted that the distance which the extended leg had to be flexed at the hip before appreciable tension developed within the nerve root corresponded roughly to the degree of limitation of straight-leg raising present before operation. Thus, in cases where this sign had been markedly positive, only a slight degree of flexion at the hip caused the nerve root at the level of the prolapse to be pulled downwards, whereas in cases where this sign was less marked a greater degree of hip flexion could be made before appreciable longitudinal tension developed within the nerve root.

In order to elucidate these phenomena we made a second set of observations on the post-mortem table. In three cadavers, all examined within two hours of death and before rigor mortis had set in, we removed the lumbar laminæ and tested the effects of the straight-leg raising mancuvre on the cauda equina. On performing this test we observed that the fifth lumbar and first sacral nerves moved downwards through their respective foramina distances of from 2 to $6 \mathrm{~mm}$., and that this movement did not begin until the leg was flexed about $30^{\circ}$ to $40^{\circ}$ from the table, and was greatest as the leg was moved from $60^{\circ}$ to $90^{\circ}$ of flexion. The fourth lumbar nerve moved downwards to a lesser extent, and the remaining lumbar nerves did not move at all. Inman and Saunders (1942) have reported similar observations.

A striking difference between these observations on cadavers and our observations on living subjects was that in patients in whom limitation of straight-leg raising was marked the downward migration of the fifth lumbar and first sacral nerves would begin after a much smaller movement of the hip. We therefore repeated our observation on cadavers, after tying a string round each extrathecal nerve root at its junction with the theca and connecting the string to a spring balance (Table II). If a constant longitudinal tension of $400 \mathrm{~g}$. was applied to the nerve in order to take up the slack, we found that as the hip was flexed to a right angle the first sacral nerve would be pulled downwards for a distance of up to $12 \mathrm{~mm}$. through its intervertebral foramen, while the nerves above it would be pulled down for successively shorter distances until the third lumbar nerve, which did not move at all. If movements of the nerve roots through the intervertebral foramina were prevented, a longitudinal strain of up to 3.2 kilos $(7 \mathrm{lb}$.) would develop within the first sacral nerve root; and proportionately lesser strains with the other roots. We also measured the breaking strains of the extrathecal roots, and found that a longitudinal tension of approximately 4.6 kilos (10 lb.) would snap the first sacral nerve, a strain which was not much greater than the strain of $3 \cdot 2$ kilos $(7 \mathrm{lb}$.) developing in the nerve when its downward movement was prevented.

8. Types of Strain Involving Affected Nerve Roots. - Now this state of affairs is paralleled by what occurs in sciatica due to intervertebral disc prolapse. The prolapse restricts the free movement of the fifth lumbar and first sacral nerve root through their respective intervertebral foramina, especially when the prolapse is wedged in the angle between the extrathecal nerve root and the theca. Often 
TABLE II

EFFECTS OF STRAIGHT-LEG RAISING TO A RIGHT ANGLE ON LUMBAR AND SACRAL NERVE ROOTS IN THE CADAVER

\begin{tabular}{|c|c|c|c|c|c|c|c|c|c|}
\hline \multirow[t]{2}{*}{ Nerve root } & \multicolumn{3}{|c|}{$\begin{array}{l}\text { Distance traversed by } \\
\text { nerve root (under } \frac{1}{2} \mathrm{lb} \text {. strain) }\end{array}$} & \multicolumn{3}{|c|}{$\begin{array}{l}\text { Longitudinal strain developed } \\
\text { if nerve root is held fixed }\end{array}$} & \multicolumn{3}{|c|}{ Breaking strain of nerve root } \\
\hline & 1st body & 2nd body & 3rd body & 1st body & 2nd body & 3rd body & 1st body & 2nd body & 3rd body \\
\hline 1st sacral .. & $\begin{array}{l}0.5 \mathrm{in} . \\
(13 \mathrm{~mm} .)\end{array}$ & $\begin{array}{c}0.5 \mathrm{in} . \\
(12 \mathrm{~mm} .)\end{array}$ & $\begin{array}{c}0.5 \mathrm{in} . \\
(12-\mathrm{mm} .)\end{array}$ & $\begin{array}{c}7-7 \cdot 5 \mathrm{lb} \\
(3 \cdot 2-3 \cdot 4 \text { kilo })\end{array}$ & $\begin{array}{c}7 \mathrm{lb} . \\
(3 \cdot 2 \text { kilo })\end{array}$ & $\begin{array}{c}7 \mathrm{lb} . \\
(3 \cdot 2 \mathrm{kilo})\end{array}$ & $\begin{array}{l}10 \mathrm{lb} . \\
(4 \cdot 6 \text { kilo })\end{array}$ & $\begin{array}{l}8 \mathrm{lb} . \\
(3 \cdot 6 \mathrm{kilo})\end{array}$ & $\begin{array}{l}10 \mathrm{lb} \text {. } \\
\text { (4.6 kilo) }\end{array}$ \\
\hline 5th lumbar .. & $\begin{array}{l}0.4 \mathrm{in} . \\
(10 \mathrm{~mm} .)\end{array}$ & $\begin{array}{l}0.3 \mathrm{in} . \\
(8 \mathrm{~mm} .)\end{array}$ & $\begin{array}{c}0.4 \mathrm{in} . \\
(10 \mathrm{~mm} .)\end{array}$ & $\begin{array}{l}5 \cdot 5-6 \mathrm{lb} . \\
(2 \cdot 5-2 \cdot 7 \text { kilo })\end{array}$ & $\begin{array}{c}5 \mathrm{lb} . \\
(2 \cdot 3 \mathrm{kilo})\end{array}$ & $\begin{array}{l}6.5 \mathrm{lb} . \\
(3 \mathrm{kilo})\end{array}$ & $\begin{array}{l}10 \mathrm{lb} . \\
(4 \cdot 6 \text { kilo })\end{array}$ & $\begin{array}{l}6.5 \mathrm{lb} \\
(2 \cdot 9 \mathrm{kilo})\end{array}$ & $\begin{array}{l}7 \mathrm{lb} \text {. } \\
(3 \cdot 2 \mathrm{kilo})\end{array}$ \\
\hline 4th lumbar... & $\begin{array}{l}0.3 \mathrm{in} . \\
(8 \mathrm{~mm} .)\end{array}$ & $\begin{array}{l}0.2 \mathrm{in} . \\
(5 \mathrm{~mm} .)\end{array}$ & $\begin{array}{l}0.2 \mathrm{in} . \\
(5 \mathrm{~mm} .)\end{array}$ & $\begin{array}{l}4-5 \mathrm{lb} \\
(1 \cdot 8-2 \cdot 3 \mathrm{kilo})\end{array}$ & $\begin{array}{l}2 \cdot 5 \mathrm{lb} \\
(1 \cdot 2 \mathrm{kilo})\end{array}$ & $\begin{array}{c}2 \mathrm{lb} . \\
(0 \cdot 9 \text { kilo })\end{array}$ & $\begin{array}{l}6 \mathrm{lb} . \\
(2 \cdot 7 \mathrm{kilo})\end{array}$ & $\begin{array}{c}5 \mathrm{lb} . \\
(2 \cdot 3 \mathrm{kilo})\end{array}$ & $\begin{array}{c}6 \mathrm{lb} . \\
(2 \cdot 7 \mathrm{kilo})\end{array}$ \\
\hline 3rd lumbar .. & $\begin{array}{l}0.2 \text { in. } \\
(5 \mathrm{~mm} .)\end{array}$ & - & - & $\begin{array}{c}1-1.5 \mathrm{lb} . \\
(0.5-0.7 \text { kilo })\end{array}$ & $\begin{array}{l}0.5 \mathrm{lb} . \\
(0.2 \text { kilo })\end{array}$ & $\begin{array}{c}0.5 \text { lb. } \\
(0.2 \text { kilo })\end{array}$ & $\begin{array}{l}? \\
?\end{array}$ & $\begin{array}{c}6 \mathrm{lb} . \\
(2 \cdot 7 \text { kilo })\end{array}$ & $\begin{array}{c}5 \mathrm{lb} . \\
(2 \cdot 3 \mathrm{kilo})\end{array}$ \\
\hline 2nd lumbar.. & - & - & - & - & - & - & $\begin{array}{l}? \\
?\end{array}$ & $\begin{array}{c}5 \mathrm{lb} . \\
(2 \cdot 3 \text { kilo })\end{array}$ & $?$ \\
\hline
\end{tabular}

also there are adhesions between the prolapse and the nerve root. The prolapse consequently produces strains of three types, within the nerve roota longitudinal strain described above, perhaps a compressive strain by squeezing the nerve root between the prolapse in front and the ligamentum flavum behind, but most important of all an angulating strain within the nerve root as it is pulled taut and bent over the prolapse. It is this latter type of strain which is probably mainly responsible for symptoms. Thus our colleagues in physiology, Dawbin and others (1947), who experimented on the effects of these various types of strain on the conductivity of nerve trunks, have shown that angulating strains of a given intensity are more effective in blocking the conductivity of nerve trunks than are longitudinal or compressive strains. Similarly those who have observed nerve trunks exposed in patients during operations under local anæsthesia, or particularly posterior nerve roots within the theca, know that these structures can be submitted to an appreciable degree of longitudinal strain without producing pain, but the moment they are forcibly angulated or are pinched considerable pain is experienced by the patient. This pain the patient refers, not to the point where the nerve is compressed, but to the zone of distribution of the nerve. The same phenomenon undoubtedly occurs in sciatica, and the shearing strains within the nerve at the point of angulation set up impulses within the nerve fibres which travel both up and down the nerve. The afferent impulses in the pain fibres of the nerve on reaching the spinal cord are relayed to the sensorium, and the sensorium naturally interprets them as coming from the peripheral endings of the pain fibres in the distribution of the affected nerve root.

9. Significance of Straight-Leg Raising Test : Evidence for Variations in Length of Affected Nerve Roots. - The actual limitation of straight-leg raising in cases of sciatica is of course due to spasm of the hamstring muscles, and this would seem to result from a reflex-mechanism initiated by increases in the strains within the affected nerve root, for the limitation can be abolished by injecting and para- . lysing the affected nerve root with a local anæsthetic solution where it crosses the disc prolapse (Falconer and others, 1947). Clinically the degree to which straight-leg raising is limited in sciatica is roughly proportional to the severity of a patient's pain (Falconer, 1944). As the patient's pain decreases when recovery occurs spontaneously or after operation, the restriction of straight-leg raising becomes proportionately less until the hip can be flexed to a right angle or more. It would seem, then, that when limitation of straight-leg raising is slight, as in cases with mild symptoms or those recovering spontaneously, there must be some slack in the nerve root which is not present in the more severe cases. We know that nerve roots can lengthen spontaneously, for Dawbin and others (1947) have observed this in experimentally produced sciatica. In a series of cats they placed a small block of wood or wax under the lowest nerve root in a position similar to that ocupied by a disc 
prolapse in man. Immediately after the block was inserted, the nerve root straddling it was always taut, but two or more weeks later when the animal was either re-explored or killed, the nerve root was always found to be slack, even though the block was still in situ. Furthermore, whereas immediately after operation the animal might limp, within a few days the limp would disappear.

There are grounds, therefore, for assuming that, as symptoms of sciatica wear off the involved nerve root elongates and slackens; for, as described earlier, the disc prolapse itself often does not subside. Conversely we may presume that when symptoms suddenly flare up in the presence of a pre-existing prolapse, some change has occurred within the nerve which tightens it and reduces the amount of slack. This change may be caused merely by slipping of the nerve root on to the summit of a prolapse. More often, probably, some sudden temporary increase in size of the disc prolapse, brought about by changes in posture of the spine or by weight-bearing, may cause the prolapse to impinge upon a nerve root, leading to intraneural contusion and œdema, which then tightens it.

10. Observations in Case of Sciatica due to a Hydatid Cyst.- In a unique case of sciatica due to a hydatid cyst (Falconer and others, 1948), we found evidence which supports the view that attacks of sciatica are more directly related to changes within the nerve roots than to the appearance of a disc protrusion. In this patient several recurrent attacks of sciatica had occurred, each initiated apparently by a fall. The hydatid cyst arose in the body of the - first piece of the sacrum and projected into the extrathecal space. It was protected everywhere from external violence by bony structures. Moreover, before operation the hydatid complement fixation and Casoni cutaneous reaction were negative, indicating that the thin-walled cyst had never leaked into the host's tissues. Therefore, as the hydatid cyst itself had undoubtedly not been affected by trauma, we can only presume that the appearance of symptoms after each fall must have been provoked by changes within the nerve roots straddling the cyst.

11. Nature of Pathological Changes within Affected Nerve Roots. - Information regarding the precise pathological changes present in sciatica within the sciatic nerve and its roots is scanty, but the known facts are consistent with the above view regarding symptom-production. The few histological reports which have been made (DennyBrown, 1933 ; Wilson, 1940 ; McKenzie, 1947) indicate that the pathological change is one of cedema rather than infiltration by an inflammatory exudate. In most instances, however, the sciatic nerve trunk seems to have been examined, and in only one case could we find a report concerning the changes within the compressed nerve root (Adams, quoted by McKenzie, 1947). It would seem that this odema can extend some distance up and down the nerve from the point of compression, and as stated earlier we have frequently seen at operation marked swelling of components of the affected nerve root within the theca. It is interesting that in McKenzie's case œdema of the nerve root was demonstrated histơlogically, although no swelling was visible to the naked eye. Undoubtedly this œdema of the nerve root and nerve trunk is analogous to that observed experimentally by Weiss (1943) and by Denny-Brown and Brenner (1944) occurring both above and below a chronic compression of a nerve trunk, and which Denny-Brown and Brenner hold is due to vascular congestion consequent upon an impairment of the blood supply of the nerve. It is our surmise that œdema within a nerve causes it to swell, and that as the nerve swells in diameter it shortens in length, and vice versa.

In addition to our observations on disc prolapse and nerve roots we made a number of otherबे observations, largely of a negative kind, which are relevant to this discussion.

\section{Other Observations}

1. Significance of Trauma.-We feel that someo authorities have overemphasized the importance of? sudden trauma in the causation of intervertebral disc protrusions. Undoubtedly it does play a part in some cases, but Schmorl and his associates (Beadle, 1931) pointed out that a premature senescence of tissues was the principal factor in producing disc degeneration, and that this was aided by " the slight shocks of normal life." This senescence may begin in some discs shortly after puberty, leading to desiccation of the nucleus pulposus and to fissuring and thinning of the annulus fibrosus. This ageing process affects the various discs throughout the spinal column to varying degrees, so that while some may degenerate early others are spared for a long time. The constantly recurring stresses and strains of an active life undoubtedly contribute to this ageing process, but, as Hyndman (1946) and others have stressed, a single severe traumatic strain is unlikely to lead to a prolapse of an intervertebral disc, unless the disc is already degenerate. Indeed, the vertebral body will fracture before a normal disc will rupture. Our own observations support this point of view, for we have already shown in the group of operated 
cases that a history of possible antecedent trauma was obtainable in only 44 out of the hundred patients.

2. Significance of Scoliosis.-Scoliosis is often seen in cases of sciatica, and when marked is often labolled " sciatic scoliosis." It was noted in exactly half our " surgical " cases, and in each instance was associated with a disc prolapse of either a projection or an extrusion type (Falconer and others, 1948). In no instance was it associated with a disc prolapse of the intermittent type (the " concealed" disc of

- Dandy), and the fact that the scoliosis was always associated with a prolapse which remained fixed in the spinal canal and was not reducible by relaxation or by postural manœuvres must surely be of some significance. The mechanism of scoliosis. is presumably one of spasm of the spinal muscles designed to splint the affected disc space in the position where the disc prolapse exerts the least possible strain on surrounding structures, particularly those with nerve filaments sensitive to pressure.

We, however, were unable to correlate the direction of the scoliotic curvature with the side of the symptoms, although we did make some observations of significance. Three examples of scoliosis occurred in cases of low-back pain without any leg pain, and as only 10 patients in the "surgical" group had never had even a trace of leg pain, the proportion of cases of scoliosis in this small minority is roughly the same as in the group with leg pain. This suggests that sciatica or nerveroot compression is not a requisite feature for "sciatic scoliosis" to develop, but that the disc prolapse alone is required. This view seems to be supported by our failure to correlate the direction. of scoliosis and the side of the symptoms in cases with sciatica. Thus of the cases with unilateral sciatica, in 25 the convexity of the primary scoliotic curve was directed to the same side as that of symptoms, while in 17 it was directed to the opposite side. Yet in both these subgroups there were instances where the summit of the disc prolapse was situated lateral to the compressed nerve root, and instances where it was situated medial to the nerve root. In 5 cases alternating scoliosis was present, and it is probably significant that in all 5 the summit of the disc prolapse was situated in the midline anterior to the theca, while in 3 of these cases the symptoms of sciatica also alternated from one leg to the other. After operation these scoliotic deformities disappeared in every instance.

3. Level of Protein in Cerebrospinal Fluid.The protein level is sometimes raised in the cerebrospinal fluid in cases of sciatica or low-back pain, and we attempted to correlate this with a number of factors, but without success. In 3 of our " surgical" cases the protein level was over $100 \mathrm{mg}$. per $100 \mathrm{c.cm}$., in 23 cases it was between 50 and $100 \mathrm{mg}$., while in 74 cases it was normal (below $50 \mathrm{mg}$.). Most of the lumbar punctures were performed between the third and fourth lumbar spines. There did not seem to be any constant relationship between the protein level and such features as the duration of symptoms, the severity of symptoms, the type of disc prolapse, the situation of the disc prolapse in relation to the theca and extrathecal nerve roots, or the presence or absence of nerve-root compression. Unfortunately for the solution of this problem the theca was opened in only a few cases, so that we were usually unable to correlate the protein levels with the appearances of the cauda equina. We noticed, however, that some of the cases with swelling and congestion of the intrathecal portion of the affected nerve roots, and even some with marked leptomeningeal adhesions (meningitis serosa circumscripta) had normal protein levels. The only definite observation was that, whenever a complete blocking of the thecal column was demonstrated by myelography, the protein content of the cerebrospinal fluid was raised. However, in this particular series of operation cases such a block was demonstrated only on three occasions.

4. Miscellaneous Observations.-Following Kellgren's work (1939) on the production of segmental pain by injecting small quantities of hypertonic saline into deep somatic structures, particularly the interspinous ligaments, some workers have been inclined to ascribe the pain of sciatica as a segmental or reflex pain due to lesions of the ligamentous structures in relation to the lower lumbar interspaces. Kellgren's work, however, has not to our knowledge yet been confirmed by other workers, and in a few patients we attempted to produce segmental pain by injecting hypertonic saline into the interspinous ligaments, but without success.

In a few of our cases of sciatica tender spots which could be described as " nodules" were observed in the muscles of the buttock and calf, and in one or two instances temporary relief of symptoms appeared to follow their infiltration with local anæsthetic solution. Some clinicians have considered these nodules to be evidence of "fibrositis," although in our case-material we always found an associated disc prolapse. Elliott (1944) recently has shown by means of electromyography that these " nodules" are due to localized areas of involuntary muscle spasm. Their precise significance, however, is still unknown.

In 30 of our early cases detailed blood examinations were performed, including leucocyte counts 
and blood sedimentation rates, without any abnormality being shown. Furthermore, in only 2 instances in the whole series was a white cell count of more than 5 cells per c.mm. observed in the cerebrospinal fluid. Consequently, we were unable to obtain the customary evidence of an inflammatory disease which would deserve the appellation of " sciatic neuritis" or of "fibrositis."

\section{DISCUSSION}

Sciatica and low-back pain are two separate clinical conditions, although they may occur together, and sciatica is commonly preceded by low-back pain. Their order of occurrence may also be reversed, and either may occur independently. Therefore they are presumably caused by different mechanisms.

Evidence has been produced to show'that a disc prolapse by itself can cause low-back pain. The posterior part of the annulus fibrosus, the posterior longitudinal ligament, and the extradural veins and other related structures are presumably supplied with sensory nerve fibres by the sinu-vertebral nerve of Luschka, which has been described in great detail by Hovelacque (1927). Attention has again been drawn to it by Roofe (1940). This nerve, which is a tiny recurrent twig arising from each spinal nerve, leaves its parent nerve distal to the spinal ganglion and, after uniting with a component branch from the sympathetic ganglionated chain, re-enters the spinal canal through the intervertebral foramen. According to Roofe and to Bradford and Spurling (1941) the type of terminal arborization of these nerve fibres suggests that they subserve pain sensibility. Presumably, then, low-back pain is due to involvement of these fibres by the disc prolapse, while the associated physical signs such as rigidity of the lumbar spine and the scoliosis noted in a proportion of cases are produced by reflex muscle spasm as a protective mechanism, designed to restrict the degree of movement occurring at the affected disc space and so to lessen the severity of the pain.

Evidence has also been advanced to show that the pain of sciatica is produced when a disc protrusion impinges upon a nerve root. The nerve root in its turn becomes œdematous, undergoing slight longitudinal shortening. As it straddles the disc prolapse, it is pulled tight against the prolapse particularly during flexion movements of the trunk and spine, while also the height of the prolapse may be increased by weight-bearing and torsional movements of the spine. The affected nerve root may then be subjected to strains of various types-longitudinal, compressive, and angulating - but it is particularly the angulating strains which provoke afferent impulses in the dorsal component of the nerve root, that pass upwards to the spinal cord, and then are relayed on to the sensorium where they produce a sensation of pain referable to the distribution of the nerve root.

The production of sciatica thus depends upon the association of two factors, the presence of a disc prolapse, and changes within the nerve root. In the absence of one or the other there may be no symptoms. As regards the two factors considered independently, we believe that, although the disc prolapse may be the primary ætiological lesion, the production of crural pain and other neurological features is more directly related to the intrinsic changes within the nerve root than to the prolapse, because if at any time, or in any manner, the longitudinal tension within the nerve root, as it lies in contact with the prolapse should lessen, symptoms will improve. This hypothesis of symptom-production in sciatica and low-back pain can also explain why these conditions, although they may occur as early as the second decade of life or as late as the seventh, most commonly occur in the fourth and fifth decades, for these are decades when disc degeneration and prolapse are usually well develo oped, and when the average man and woman are still leading an active and vigorous life. It should also be remembered that Andrae, working in 1929 at Professor Schmorl's Institute at Dresden, showed that posterior disc protrusions appeared withô increasing frequency with advancing years, and weres seen in 15.2 per cent. of 368 spinal columns examine do post-mortem (Beadle, 1931).

There are of course other proven causes of sciatica besides intervertebral disc prolapse, although they are rare, but this hypothesis can be readily adapted to include them. In the course of our operative experience we have occasionally encountered tumours of the cauda equina or of the spinal column, granulomatous disease of the intervertebral disc, and spondyloliothesis causing sciatica (Falconer and others, 1948). Tumours of the cauda equina and spinal column, for example, can act as struts against which a nerve root may be strained. It is interesting that in these cases symptoms of sciatica may be intermittent, even though the primary lesion is continuously present (as in a case of hydatid cyst referred to earlier in the text), and this supports our hypothesis that the production of symptoms is more directly related to the changes within the nerve root.

The value of an hypothesis is that it should serve as a foundation upon which to build a rational system of therapeutics. Many forms of treatment have been tried, some of which will now be considered. Experience shows that, when symptoms of sciatica and low-back pain are mild, a patient may 
often recover without special treatment, and with an ambulatory regime. Presumably in such circumstances the intrinsic changes within the nerve roots subside spontaneously, or perhaps the nerve root slips off the summit of the disc or the adhesions which may bind it to the disc give way in response to some slight trauma. When, however, symptoms are severe, only two forms of treatment need be seriously considered, namely rest and operation.

It is a great principle of therapeutics in all parts of the body to rest the injured part. Bed-rest is the usual application of this principle to sciatica, and acts both by lessening the repeated impacts of the nerve against the disc prolapse, and also in many instances by lessening the size of the protrusion through withdrawing weight-bearing. We have customarily treated our patients in the first instance by at least one month's complete rest in bed, and only if that failed have we advised surgical treatment. Many authorities, however, practise an even more positive form of rest, and immobilize the spinal column of their patient in a plaster body cast or on a Bradford frame for similar or longer periods of time. It may be argued that this is a more effective form of rest to the spine than that afforded by rest in bed, but we have no experience on which to decide this point.

Operative treatment, we feel, should be reserved only for those patients in whom treatment by rest for an adequate period of time has been tried without benefit or with only temporary relief, and in whom the disability is appreciable, so that they are unable to pursue their work in a reasonable manner. We have shown that, when performed in accordance with certain principles, the results of surgical treatment are satisfactory. There is, however, in many quarters a feeling that " once a disc protrusion, then always a disc protrusion," and that if a disc prolapse can be diagnosed now, it should be operated on, because if not the patient will develop trouble again later. Many authorities for instance state that the mere demonstration of a disc prolapse by myelography is good grounds for operation (Poppen, 1945), but we personally do not think so. Any clinician of experience can recall numbers of patients who, after suffering from a bout of severe and protracted sciatica with signs suggesting disc prolapse as the cause, became relieved of symptoms, and never subsequently suffered a recurrence (Ekvall, 1939; Dunning, 1946). Although in the short period of time in which we repeated our myelograms in the group of 10 " medical " patients who obtained relief by bed-rest, evidence of regression in the size of the prolapse after disappearance of symptoms was not forthcoming, except in one case, regression nevertheless probably occurs frequently over the years. Indeed Rabinovitch (1947), in a series of spinal columns examined postmortem, has made striking histological observations of " healing " of degenerate discs by fibrous scarring and even by bony ankylosis, while Beadle (1931) also indicates that this can occur. The pessimistic attitude concerning the late results of conservative therapy which prevails in certain quarters is therefore without foundation.

Still other forms of treatment have been recommended, but we feel that these are not as effective or as certain in their response as the two we have just considered. Manipulation of the spine under anæsthesia and stretching of the sciatic nerve by open operation may possibly act by stretching the affected nerve root and so elongating it. Perhaps it is not without significance that these procedures are occasionally followed by transient or permanent foot-drop, suggesting that the nerve has been stretched to the point of rupture. The epidural injection of large amounts of saline may act by. shifting the nerve root in relation to the prolapse or by stretching it. Finally the so-called negative explorations with subsequent and unexpected cure reported by many surgeons in cases of suspected disc lesion may be examples of intermittent prolapse (Falconer and others, 1948), in which the retraction of the nerve root consequent upon an exposure of the disc space has stretched or shifted the nerve root sufficiently to relieve symptoms.

This hypothesis of the mechanism of symptomproduction in sciatica and low-back pain, then, can explain most of the features of these two conditions, and can also be correlated with the mechanisms by which the standard therapeutic procedures probably lead to relief. We feel that upon it we can justify our belief that the treatment of intervertebral disc prolapse should in the first instance be conservative, and that surgical methods should be adopted only when conservative measures have failed.

In conclusion we may state that we have been unable to confirm the validity of such older hypotheses advanced to explain sciatica and low-back pain, as "fibrositis and sciatic neuritis" (Gowers, 1899), " sacro-iliac strain" (Baer, 1917), " arthritis of the spinal inter-articular joints" (Putti, 1927), or " contracture of the fascia lata" (Ober, 1935).

\section{SUMMARY}

Routine myelography performed in patients suffering from sciatica or low-back pain, admitted to hospital because of severity or intractability of symptoms, has indicated that intraspinal lumbar disc protrusions are present in almost all cases, whether the patient will later recover from symptoms 
spontaneously, or only after the operative removal of the disc prolapse.

Myelography, when repeated after spontaneous recovery from symptoms has occurred, usually shows that the intraspinal disc prolapse persists apparently unchanged.

A number of further clinical observations are reported, which indicate that low-back pain is caused by the disc prolapse alone, presumably through implication of the sinu-vertebral nerve of Luschka, and that sciatica occurs only when the disc prolapse is so situated that it impinges upon a nerve root in its extrathecal course, at the level of either of the lower two lumbar intervertebral discs. Secondary changes, probably of intraneural œdema, appear within the affected nerve root, which contribute to the production of symptoms by pulling the nerve root tight against the disc prolapse, thereby causing angulating and other strains within it. These strains in their turn excite afferent impulses within the nerve, which on reaching the sensorium produce a sensation of pain referable to the peripheral distribution of the affected nerve root. A slight blocking in conductivity through the compressed segment of nerve root accounts for the associated muscular, sensory, and reflex disturbances. The spontaneous remission of symptoms, which often occurs in sciatica, can result from a resolution of the neural changes without an associated resolution of the disc prolapse.

In treating sciatica and low-back pain conservative measures applying the principle of rest to the lumbar spine should always be tried in the first instance, and are often successful. Surgical treatment should only be considered when conservative measures fail and disability is appreciable.

We wish to thank the Medical Research Council of New Zealand for defraying the expenses incidental to this investigation; also our many colleagues for their help and encouragement, particularly Professor J. C. Eccles of the Department of Physiology. In addition one of us (M.A.F.) wishes to thank the Nuffield Foundation for the award of a travelling grant, which enabled him to discuss the investigations with many workers in both Canada and the United Kingdom, and so crystallize his ideas.

\section{REFERENCES}

Baer, W. S. (1917). Johns Hopk. Hosp. Bull., 28, 159.

Beadle, O. A. (1931). "The Intervertebral Discs." M. R. C. Spec. Rep., No. 161. London.

Begg, A. C., Falconer, M. A., and McGeorge, M. (1946). Brit. J. Surg., 34, 141.

Bradford, F. K., and Spurling, R. G. (1941). "The Intervertebral Disc." Springfield, Illinois.

Dawbin, W., Cole, D. S., and Glasgow, G. L. (1947). (Personal communication.)

Denny-Brown, D. (1933). Proc. roy. Soc. Med., 26, 1399.

_, and Brenner, C. (1944). Arch. Neurol. Psychiat., Chicago, 52, 1.

Dunning, H. S. (1946). Ibid., 55, 573.

Elliott, F. A. (1944). Lancet, 1, 47.

Ekvall, S. (1939). Acta med. Scand., 101, 1.

Falconer, M. A. (1944). N. Z. med. J., 43, 58.

- Glasgow, G. L., and Cole, D. S. (1947). J. Neurol. Neurosurg. Psychiat., 10, 72.

- McGeorge, M., and Begg, A. C. (1948). Brit. $J$. Surg., in press.

Gowers, W. R. (1899). "Manual of Diseases of the Nervous System." London

Holmes, J. M., and Sworn, B. R. (1945). Brit med. JW $2,350$.

Hovelacque, A. (1927). " Anatomie des nerfs cranien要 et rachidiens et du système sympathique chez l'homme. Paris.

Hyndman, O. R. (1946). Arch. Surg., 53, 247.

Inman, V. T., and Saunders, J. de C. M. (1942). Radis ology, 38, 669.

Kellgren, J. H. (1939). Clin. Sci., 4, 35.

Knutsson, F. (1942). Acta Radiol., 23, 431.

Lindblom, K. (1944). Ibid., 25, 195.

McKenzie, D. (1947). Austral. N.Z. J. Surg., 16, 219.

Munro, D. (1945). New Engl. J. Med., 232, 149.

Ober, F. R. (1935). J. Amer. med. Ass., 104, 1580.

O'Connell, J. E. A. (1943). Brit. J. Surg., 30, 315.

Poppen, J. L. (1945). New Engl. J. Med., 232, 211.

Putti, V. (1927). Lancet, 2, 53.

Rabinovitch, I. (1947). (Personal communication.)

Roofe, P. G. (1940). Arch. Neurol. Psychiat., 44, 100.

Weiss, P. (1943). Anat. Rec., 86, 491.

Wilson, S. A. K. (1940). "'Neurology." London. 